NBER WORKING PAPER SERIES

\title{
UNEMPLOYMENT AND INNOVATION
}

\author{
Joseph E. Stiglitz \\ Working Paper 20670 \\ http://www.nber.org/papers/w20670 \\ NATIONAL BUREAU OF ECONOMIC RESEARCH \\ 1050 Massachusetts Avenue \\ Cambridge, MA 02138 \\ November 2014
}

This paper is part of a broader work on innovation, undertaken with my colleague Bruce Greenwald, and of a more long standing research agenda undertaken with Partha Dasgupta. I also wish to acknowledge my indebtedness to Peter Howitt, and to discussions over the years on these topics with Giovanni Dosi. My interest in these topics was awakened as a graduate student by Paul Samuelson and Charles Kindleberger, who approached these questions from quite different perspectives. I also wish to acknowledge financial support from the Institute for New Economic Thinking (INET) and research and editorial assistance from Laurence Wilse-Samson, Eamon Kircher-Allen, and Jun Huang. The views expressed herein are those of the author and do not necessarily reflect the views of the National Bureau of Economic Research.

NBER working papers are circulated for discussion and comment purposes. They have not been peerreviewed or been subject to the review by the NBER Board of Directors that accompanies official NBER publications.

(C) 2014 by Joseph E. Stiglitz. All rights reserved. Short sections of text, not to exceed two paragraphs, may be quoted without explicit permission provided that full credit, including $\mathbb{C}$ notice, is given to the source. 
Unemployment and Innovation

Joseph E. Stiglitz

NBER Working Paper No. 20670

November 2014

JEL No. E24,O30,O31,O33

\begin{abstract}
$\underline{\text { ABSTRACT }}$
This paper analyzes equilibrium, dynamics, and optimal decisions on the factor bias of innovation in a model of induced innovation. In a model with full employment, we show that (a) if the elasticity of substitution is always less than or greater than unity, there is a unique steady state equilibrium; (b) if the elasticity of substitution is less than unity, the steady state is stable, but convergence is oscillatory; (c) if the elasticity of substitution is greater than unity, the steady state is a saddle point; and (d) if the elasticity of substitution is less than unity for both high and low effective capital labor ratios but greater than unity for intermediate values, then there can be multiple steady states. In a model where efficiency wages lead to equilibrium unemployment, we show that if the elasticity of substitution is less than unity, there will be a bias towards excessive labor augmenting innovation, resulting in too high unemployment, with convergence to the unique steady state being oscillatory, rather than monotonic. Similarly, if the elasticity of substitution between skilled and unskilled labor is less than unity, and there is efficiency wage unemployment for unskilled labor only, there is will be excessively skill-biased innovation.
\end{abstract}

This paper provides an alternative resolution to the Harrod-Domar conundrum of the disparity between the natural and warranted rate of growth to that of Solow, with strong policy implications, for instance, concerning the effects of income distribution and monetary policy both in the short run and the long.

\author{
Joseph E. Stiglitz \\ Uris Hall, Columbia University \\ 3022 Broadway, Room 212 \\ New York, NY 10027 \\ and NBER \\ jes322@columbia.edu
}




\title{
Unemployment and Innovation
}

\author{
Joseph E. Stiglitz ${ }^{1}$
}

There has long been a presumption that innovations represent a societal Pareto improvement. Historically, there have often been instances in which significant groups within societies have resisted innovation, most notably the Luddites in the beginning of the nineteenth century, who saw modern machines as leading to unemployment and impoverishment. While increases in productivity could in principle make everyone better off-the production possibilities curve moves out-in practice there are always winners and losers. Innovations that reduce the demand for unskilled workers decrease their wages, even if they increase the wages of skilled workers. The statement that such skill-biased innovation could be welfare enhancing is usually taken to mean that the gains of the skilled workers are more than sufficient to compensate the losses of the unskilled workers. But while the skilled workers could compensate the unskilled workers, such compensation seldom occurs. And if, as has been happening in the United States and many other advanced industrial countries, the losers are those at the bottom of the income distribution, then innovation can contribute to growing inequality. In this situation, whether societal welfare is increased depends on how one weighs the benefits to the relatively rich against the losses to the relatively poor. ${ }^{2}$

More recently, however, it has been shown that with market imperfections and societal rigidities, all (or at least most) groups in society can be worse off. In the 1920s, productivity increases in agriculture were so large-especially given the inelasticity of demand for agricultural goods - that incomes in the sector declined. With perfect mobility, the surplus agricultural workers would have moved into the urban sector. But there are significant costs to the mobility of labor, and with wages in agriculture declining and the value of rural assets (like houses) declining as well, many in that sector couldn't afford to move to the city and obtain the skills that would make them productive there. Worse still, neither they nor the banks that provided credit anticipated these events. Hence, as incomes in the rural sector collapsed, those in that sector were left with a legacy of debt burdens and banks faced massive losses. The result was a marked decline in demand for urban goods - so great that incomes in the urban sector itself fell. Innovation may have helped precipitate the Great Depression.

We have argued, by the same token, that improvements in productivity in manufacturing, leading to decreased employment and wages in that sector, have contributed to the current

\footnotetext{
${ }^{1}$ University Professor, Columbia University. This paper is part of a broader work on innovation, undertaken with my colleague Bruce Greenwald, and of a more long standing research agenda undertaken with Partha Dasgupta. I also wish to acknowledge my indebtedness to Peter Howitt, and to discussions over the years on these topics with Giovanni Dosi. My interest in these topics was awakened as a graduate student by Paul Samuelson and Charles Kindleberger, who approached these questions from quite different perspectives. I also wish to acknowledge financial support from the Institute for New Economic Thinking (INET) and research and editorial assistance from Laurence Wilse-Samson, Eamon Kircher-Allen, and Jun Huang.

${ }^{2}$ Greenwald and Kahn (2009) have shown that most of the decrease in manufacturing employment, at least prior to 2000, was a result of improvements in technology (rather than globalization.). There is a large literature supporting the view that innovation in the US has been "skill-biased." See e.g. Greiner, Rubart, and Semmler (2003); Goldin and Katz (2008), Autor and Dorn (2013), Autor et al 2003, 2008.
} 
economic slowdown. Innovation requires economic restructuring, and markets often do not manage such restructurings well. But as firms make decisions that affect the pace and direction of innovation, they do not take these general equilibrium effects into account. Each small firm takes the course of wages and unemployment, for instance, as given; but collectively, as they make their innovation decisions, they affect the evolution of wages and unemployment. Unfettered and undirected markets may result in patterns of learning and innovation that result in more inequality and higher unemployment than is socially desirable. There are other patterns that would enhance societal well-being.

These results should not come as a surprise, for they reflect the general proposition that there are marked discrepancies between private rewards and social returns, especially when it comes to innovation and/or when there are imperfections of information and incomplete marketsthat is, always (Greenwald and Stiglitz 1986). In this paper, I construct a simple model examining the factor bias of technological change (i.e. the extent to which it is labor- or capitalaugmenting, or skilled- or unskilled-biased), to show that the market solution is not Pareto efficient. In the particular model examined here, we establish that there is excessive laborsaving technological change, and that the equilibrium unemployment rate that emerges is too high. ${ }^{3}$ We also demonstrate a fundamental instability in the equilibrium dynamics when the elasticity of substitution is greater than unity: while there is a steady state equilibrium, it is a saddle-point, and slight deviations from the convergence path can lead to extreme outcomes.

To see these results more clearly, we focus on a simple model where there are a large number of identical firms, each of which faces a decision about the direction of innovation - whether to focus on, say, making labor or capital more productive, or skilled or unskilled labor more productive. This can come about as a result of either devoting efforts at learning or investing resources to $R$ \& $D$.

The paper is divided into four sections, besides this introduction and the conclusion. In section I, we present the basic model, where we focus on the decision to increase the productivity of labor or capital. Section II extends the analysis to a dynamic context in a standard neoclassical model with full employment, while Section III extends the model to one where there is unemployment because of real wage rigidities arising from efficiency wage concerns. Section IV shows how the same framework can be used to analyze the choice of whether technological change should improve the productivity of skilled or unskilled workers.

\footnotetext{
${ }^{3}$ This paper builds builds off a large literature on factor biased induced innovation, going back to Ahmad (1966), Drandakis and Phelps (1966), Fellner (1961), Kennedy (1964), and Samuelson (1966), with antecedents in the literature in economic history (e.g. Salter, 1962, Habakkuk, 1962). More recent work includes that of Acemoglu (e.g. Acemoglu 2010).
} 


\section{The Basic model}

II.

First, we assume a simple aggregate production function with constant returns to scale of the form

$$
Q=F\left(\mu^{t+1} K, \lambda^{t+1} L\right),
$$

where $Q$ is output, $K$ is the capital stock, and $L$ is the labor supply. $\mu \mathrm{K}$ and $\lambda \mathrm{L}$ are the effective capital and labor supply. If we set $\mu^{t}$ and $\lambda^{t}=1$, then $\mu^{t+1}$ and $\lambda^{t+1}$ measure the level of capital and labor-augmenting technological progress respectively between period $t$ and $t+1$. In the following discussion, without ambiguity, we drop the superscript on $\lambda$ and $\mu$.

Because of constant returns to scale, we can write

$Q / \lambda L=f(\mu k / \lambda)=f(k)$

where $k=K / L$, the capital-labor ratio, assumed for the moment as given, $f$ is output per unit of effective labor, and $\mathrm{k} \equiv \mu \mathrm{k} / \lambda$, the effective capital-labor ratio.

We make use of the well-established concept of the innovation possibilities curve, postulating that there is a trade-off between $\mu$ and $\lambda$, as depicted in figure 1: one can only have more capital augmenting technological progress by giving up on labor augmenting technological progress. We represent by $A$ and $B$ the points where the slope of $Z$ is respectively 0 and infinity, and assume that at $A, \mu>1$ and at $B, \lambda>1$ and $\mu<1$.

(1.2) $\mu=Z(\lambda), Z^{\prime} \leq 0, Z^{\prime \prime} \leq 0$.

If the rate of labor augmenting technological progress is to increase, capital augmenting progress must decrease; and as $\lambda$ increases, the sacrifice in $\mu$ becomes greater.

Each firm takes next period's wages $W$ and cost of capital $R$ as given (for later reference, we refer to the wage per efficiency unit as $w$ and the cost of capital per efficiency unit as $r$ ), and maximizes the next period's profits ${ }^{4}$

(1.3) $\max Q-W L-R K$,

where $\mathrm{W}$ is the wage per worker and $\mathrm{R}$ is the cost of a unit of capital,

yielding ${ }^{5}$

\footnotetext{
${ }^{4}$ Similar results obtain in a more dynamic, multi-period model.

${ }^{5}$ Each firm takes factor prices as give. We use the first order conditions for $K, L$, and $\lambda$ :

$\mathrm{F}_{\mathrm{L}} \lambda=\mathrm{W}$, or $\mathrm{F}_{\mathrm{L}}=\mathrm{w}$

$F_{K} \mu=R$, or $F_{K}=r$

$F_{K} Z^{\prime} K+F_{L} L=0$,

or

$Z^{\prime}=w L / r K$,

where $w \equiv W / \lambda, r \equiv R / \mu$
} 
(1.4) $W L=-R K d(\ln Z) / d(\ln \lambda)$

or

$(1.5) z(\lambda) \equiv-d(\ln Z) / d(\ln \lambda)=s_{L} / s_{K}$,

where $s_{\mathrm{L}}$ and $\mathrm{s}_{\mathrm{K}}$ are the share of labor and capital in national income, respectively. Optimization entails setting the (absolute value of the) elasticity of the innovation possibilities curve equal to the relative shares. But the relative shares themselves are a function of $\lambda$ :

(1.6) $s_{K}=1-s_{L}=f^{\prime}(Z(\lambda) K / \lambda L) \mu K / Q=f^{\prime}((Z(\lambda) k / \lambda) Z(\lambda) k / \lambda) / f\left((Z(\lambda) k / \lambda) \equiv s_{K}(\lambda ; k)\right.$.

The equilibrium "direction" (or bias) of innovation is given by the solution to ${ }^{6}$

(1.7) $z\left(\lambda^{*}\right)=s_{L}\left(\lambda^{*}, k\right) /\left[1-s_{L}\left(\lambda^{*}, k\right)\right]$,

where for the moment $k$, the capital-labor ratio, is assumed fixed. Thus, (1.7) can be solved for the equilibrium factor bias $\left\{Z\left(\lambda^{*}\right), \lambda^{*}\right\}$.

Figure 2 graphically depicts the solution to (1.7). Straightforward calculations show that $\mathrm{z}$ is an increasing function of $\lambda$ (under our assumptions concerning $Z$ ). An increase in $\lambda$ lowers the effective capital-labor ratio. When the elasticity of substitution is less than unity, this means that the share of labor decreases, so there is a unique value of $\lambda$ for which the elasticity of the innovation curve equals the relative shares, illustrated in Panel A. When the elasticity of substitution is greater than unity, the share of labor increases as $\lambda$ increases, so there may be multiple values of $\lambda$ for which the elasticity of the innovation curve equals relative shares. ${ }^{7}$

\section{Long-Run Dynamics and Factor-Biased Technological Progress}

In the previous section, we assumed that the capital stock was fixed. Over time, however, it increases. In this section, we describe the long-run dynamics of the economy. This section is divided into three parts. In the first, we present the model; in the second, we describe the steady state, and in the third, we analyze the dynamics.

\footnotetext{
${ }^{6}$ The share of labor is simply a function of $\lambda$, if $K, L$, and the unemployment rate are all fixed. In the standard models, the unemployment rate is zero. In the discussion below, we allow the unemployment rate to be endogenous.

${ }^{7}$ The simple formulation of this section has elided a key issue, that of timing. Firms choose a research strategy today--a choice of factor bias--based on their expectations of factor prices in the future. But those choices (collectively) affect factor prices. The results above imply that if the elasticity of substitution is greater than unity, then if firms expect the share of labor to be high, then embark on research strategies that will, in fact, ensure that the share of labor is high; while if they expect the share of labor to be low, they embark on research strategies which ensure that the share of labor is small. There are multiple momentary rational expectations equilibria.
} 


\section{II.1 Long-run dynamics with full employment}

When the elasticity of substitution is high, an increase in capital augmenting technological change increases the share of capital (other things being equal) leading to further increases in the rate of capital augmenting technological progress. It is well known from standard growth theory that a steady state requires that technological change be pure labor augmenting. This suggests that if the elasticity of substitution is greater than unity, the steady state equilibrium may be unstable. The analysis below shows that that is in fact the case, and that if the elasticity of substitution is less than unity, the equilibrium is stable, but that convergence to the equilibrium may not be monotonic.

We simplify by assuming a fixed savings rate (this assumption can be generalized, at the cost of some complexity).

$(2.1) \mathrm{I}=\mathrm{sQ}=\mathrm{dK} / \mathrm{dt}$

where $\mathrm{s}$ is the savings rate, $\mathrm{I}$ is investment, and $\mathrm{K}$ is (as before) the capital stock, so that

(2.2) $d(\ln K) / d t=S Q / K=S \mu f(K) f(K) / K$.

We again postulate a trade-off between labor-augmenting and capital-augmenting technological progress, reflected in an innovation possibilities frontier as before, this time expressed though in terms of trade-offs in the rates of labor and capital augmenting progress, with

(2.3) $\quad \operatorname{dln} \mu / d t \equiv m=Z(\Lambda)$,

where

(2.4) $\Lambda \equiv \mathrm{dln} \lambda / \mathrm{dt}$.

From the discussion of section I, it should be clear that ${ }^{8}$

$(2.5) z(\Lambda) \equiv-d(\ln Z) / d(\ln \Lambda)=s_{L} /\left(1-s_{L}\right) \equiv \Phi(\kappa)$,

where

(2.6) $\Phi^{\prime}(\mathrm{k})>$ or $<0$ as $\sigma<$ or $>1$.

\footnotetext{
8 The rate of reduction of unit output costs is $\lambda s_{L} \mu s_{K}$. Thus (2.5) can be seen as maximizing the rate of reduction of the unit costs of production. A fully dynamic specification would take into account not only current market shares but also future market shares, i.e. reductions in costs of production not only today, but at future dates. Since in steady state, shares are constant, this distinction makes no difference in that context. However, as we noted in the earlier section, what firms care about today in choosing their research strategy is factor prices (shares) in the future, which themselves are endogenous, there can again exist multiple momentary equilibria if the elasticity of substitution is greater than unity. The dynamics described below assume myopic expectations; the dynamics in the more general case are even more complicated.
} 
Given our assumptions concerning the innovation possibilities curve, we can solve (2.5) for the rate of labor and capital augmenting technological change as a function of $\mathrm{k}$ :

(2.7) $\Lambda=z^{-1}(\Phi(\kappa)) \equiv \theta(\kappa)$.

and

(2.8) $d \ln \mu / d t=m=Z(\Lambda)=Z(\theta(k))$.

For any given $\mathrm{k}$, there is a unique value of $\Lambda$--a well-specified bias of technical change. But unless the elasticity of substitution is unambiguously greater or less than unity, $\wedge$ may not be monotonic in $\mathrm{K}$. If the elasticity of substitution is greater than unity, an increase in $\mathrm{k}$ leads to an increased share of profits and therefore a decrease in $\Lambda$ and conversely if the elasticity of substitution is less than unity:

(2.9) $\theta^{\prime}(\mathrm{k})>$ or $<0$ as $\sigma<$ or $>1$.

We assume that there is a maximum and minimum value of $m$ and $\Lambda ; m_{\max }$ is achieved when $s_{L}$ $=0 ; \Lambda_{\max }$ is achieved when $\mathrm{s}_{\mathrm{L}}=1$; conversely for $\Lambda$.

Letting the rate of growth of the labor force be $n$, we can describe the dynamics of the economy by the pair of equations (2.8) and

(2.10) $d \ln \kappa / d t=S \mu(f(\kappa) / k)+Z(\theta(\kappa))-\theta(\kappa)-n=S \mu(f(k) / k)-\zeta(\kappa)$,

where

$\zeta(\kappa) \equiv n+\theta(\kappa)-Z(\theta(\kappa))$.

\section{II.2 Steady states}

The steady state is given by the solution to

(2.11a) $Z\left(\theta\left(\kappa^{*}\right)\right)=0$

(2.11b) $\mu^{*}=\left[n+\theta\left(\kappa^{*}\right)-Z\left(\theta\left(\kappa^{*}\right)\right)\right] \kappa^{*} / S f\left(\kappa^{*}\right)=\zeta\left(k^{*}\right) K^{*} / S f\left(k^{*}\right)$

(2.11a) can be solved for $\mathrm{K}^{*}{ }^{9}$ (If the elasticity of substitution is everywhere either below or above unity, then there is a unique solution to 2.11a. Otherwise, there may be multiple solutions.)

Given $\mathrm{K}^{*},(2.11 \mathrm{~b})$ can be solved uniquely for $\mu^{*}$.

Figure 3 provides a diagrammatic solution. The $d \ln \mu / d t=0$ locus is a vertical line at $\mathrm{K}=\mathrm{K}^{*}$.

\footnotetext{
${ }^{9}$ There always exists a solution to (2.11a) provided that there exists some $\mathrm{k}$ for which $\Phi(\mathrm{k})=\mathrm{z}\left(\Lambda^{*}\right)$, where $\Lambda^{*}$ is the value of $\Lambda$ for which $d \ln \mu / d t=0$, i.e. $Z\left(\Lambda^{*}\right)=0$. This will always be the case if the elasticity of substitution is bounded above or below unity.
} 
On the other hand, from (2.11b)

$$
\operatorname{dln} \mu / d k=\left(\zeta^{\prime}(k) k / \zeta\right)+1-s_{K},
$$

where

$$
\zeta^{\prime}(\mathrm{k})>\text { or }<0 \text { as } \sigma<\text { or }>1 \text {, }
$$

i.e. if the elasticity of substitution is less (greater) than unity, as $\mathrm{k}$ increases, the share of labor increases (decreases), so $\theta-Z$, the difference between the rate of labor and capital augmenting progress, increases (decreases).

If the elasticity of substitution is less than unity, there are then two cases: for $n$ small, at $k=0$, $\zeta(\mathrm{k})<0$. Define $\mathrm{K}^{* *}$ as the solution to

$$
(2.12) \zeta\left(\mathrm{K}^{* *}\right)=0
$$

Then the $\mathrm{dln} \mu / \mathrm{dt}=0$ locus hits the horizontal axis at $\mathrm{K}^{* *}$; and it is clear that $\mathrm{K}^{* *}<\mathrm{K}^{*}$.

On the other hand, if $\mathrm{n}$ is large, it is possible that even when $s_{L}=0, \zeta(\kappa)>0$, in which case (2.11b) is an upward sloping curve which hits the vertical axis at $\mu=0$ under standard assumptions on the production function. ${ }^{10}$ Figure $3 \mathrm{~A}$ illustrates this case. .

On the other hand, if the elasticity of substitution is greater than unity, then $\zeta$ is a negatively sloped function of $\mathrm{k}$, and the $\mathrm{dln} \mu / \mathrm{dt}=0$ locus hits the horizontal axis at $\mathrm{K}=0$ and at $\mathrm{K}=\mathrm{K}^{* *}$ where $\mathrm{K}^{* *}$ is again given by $(2.12)$ and where now $\mathrm{K}^{* *}>\mathrm{K}^{*}$. Figure $3 \mathrm{~B}$ shows the inverted $\mathrm{U}$ shaped curve. ${ }^{11}$

Figure $3 \mathrm{C}$ shows the case where the elasticity of substitution is less than unity for large and small values of $\mathrm{k}$, but in between it is greater than unity. In the case exhibited, there are three values of $\mathrm{k}$ for which $\mathrm{dln} \mu / \mathrm{dt}=0$.

\section{II.3 Dynamics}

Above the $\mathrm{dln} \mathrm{k} / \mathrm{dt}=0$ curve, $\mathrm{k}$ is increasing, while if the elasticity of substitution is less than unity, to the right of the $m=0$ locus, $\mu$ is decreasing. The phase diagram shows an oscillatory convergence to equilibrium (Illustrated in Figure 3A).

The case where the elasticity of substitution is greater than unity is more complicated. The steady state is an unstable saddlepoint, with the economy normally converging either to a situation where $\mathrm{k}=0$ or infinity (the asymptotic share of labor either is zero or one). If the economy gets into a situation where the effective capital labor ratio is too high (above the equilibrium trajectories going into $\left(\mathrm{K}^{*}, \mu^{*}\right)$, the share of capital is "too high," technology becomes capital augmenting, leading the effective capital labor ratio to increase still further.

\footnotetext{
${ }^{10}$ Where limit of $f / k$ as $k \rightarrow 0$ is infinity

${ }^{11}$ The $m=0$ curve may actually have multiple peaks and exhibit more complicated dynamics that illustrated.
} 
On the other hand, if the economy is initially at any value of $\{k, \mu\}$ below the equilibrium trajectories, $\mu$ and $\mathrm{k}$ both approach zero. (Figure $3 \mathrm{~B}$ ).

Figure $3 \mathrm{C}$ illustrates the case with multiple steady states as a result of the fact that the elasticity of substitution for low and high values of $k$ is less than unity, but for intermediate values of $k$ is greater than unity. Then for initial conditions below the trajectory $A E_{2}$ or $B_{2}$ the economy converges to $E_{1}$, while for any set of initial conditions above $A E_{2} B$ the economy converges to $E_{3}$. (In both cases, the convergence is oscillatory.)

Proposition 2. The economy with endogenous factor bias is stable if the elasticity of substitution is less than unity but convergence may not be monotonic; but the economy is dynamically unstable if the elasticity of substitution is greater than unity.

These instability results are a consequence of the strong assumption that the innovation frontier itself is invariant to the value of labor and capital augmentation previously achieved. If, for instance, the economy has increasingly focused on labor-augmenting technical progress because of the increasing share of labor, further labor augmentation might becomes more difficult. Thus, even at the high share of labor, there would be a shift towards capitalaugmenting technological progress. By contrast, with the possibility of "learning to learn," the process of factor biased technological change may feed upon itself, i.e. as the economy engages in say labor augmenting technological progress, it becomes more skilled at learning how to save labor (relative to saving capital).

In the case of an elasticity of substitution greater than unity. it is worth observing the limiting values of some of the relevant variables. When $\mathrm{k}$ goes to zero ( $\mathrm{s}_{\mathrm{L}}$ goes to 1 ), even as the effective capital labor ratio is shrinking, per capital income, $\lambda f$ is increasing, at an asymptotic rate of $\Lambda_{\max }$, which is considerably higher than the rate of increase in the steady state, where it is just $\Lambda^{*}$, given by (2.7a) ,

$$
\Lambda^{*}=\mathrm{z}^{-1}\left(\Phi(\mathrm{\kappa})^{*}\right) \equiv \theta\left(\mathrm{K}^{*}\right),
$$

where $\mathrm{K}^{*}$ is given by (2.11a).

When $\mathrm{k}$ goes to infinity ( $s_{\mathrm{k}}$ goes to 1 ), it can be shown that dln $\mathrm{k} / \mathrm{dt}$ may grow without bound. The limiting case of an infinite elasticity of substitution production function, $f=\alpha+\beta k$, illustrates what can happen. $d \mathrm{ln} \kappa / d t$ approaches $S \mu \beta+Z_{\max }-\Lambda_{\min }-n$, where $Z_{\max }$ and $\Lambda_{\min }$ are, respectively, the maximum rate of capital augmenting technological progress and the minimum rate of labor augmentation, achieved when the share of capital is unity, so that, in the limit, $\mu$ is increasing at the rate of $Z_{\max }$. Hence $k$ is increasing superexponentially. The rate of growth of output per worker is approximately

$$
\Lambda_{\min }+\mathrm{S} \mu \beta,
$$

which increases without bound. Workers' income, on the other hand, is $\lambda \alpha$, which decreases at the rate of $\Lambda_{\text {min }}$; while income per capita is increasing without bound, not only does the share of wages go to zero, but the income of workers' does too, if $\Lambda \min <0$, which it well may be. If $\Lambda$ $\min =0$, worker incomes stagnate. 


\section{Unemployment equilibrium}

\section{III.1 Short-run equilibrium}

Now assume, as in Shapiro and Stiglitz (1984), that as the level of unemployment decreases, the wage that firms must pay increases (in that model, to avoid shirking; in other models, similar results obtain as a result of a bargaining process). Then an increase in productivity of labor (that is, a labor augmenting technological change) and a corresponding decrease in the productivity of capital (along the innovation frontier) may shift the demand curve for labor up or down, depending on the elasticity of substitution. The marginal return to an effective labor unit is

(3.1) $W / \lambda=f(K)-K f^{\prime}(\kappa) \equiv g(\kappa)$

Hence

(3.2) $L^{d}=Z K / \lambda g^{-1}(W / \lambda)$

An increase in $\lambda$ shifts the demand curve for labor. Figure 4 shows how a shift in the demand curve for laborers affects the equilibrium unemployment.

Proposition 3. If the demand for laborers decreases as a result of a change in technology (innovation is labor saving, in the sense that at any wage, the demand for workers decreases ${ }^{12}$ ) then unemployment increases.

It is easy to show that if the elasticity of substitution is less (greater) than unity, then (at the equilibrium wage), an increase in productivity of each worker (a labor augmenting technological change) leads to a reduced (increased) demand for workers.

\section{III.2 Social welfare maximization}

Assuming that costless redistributions are possible, social welfare is maximized by maximizing national output with respect to $\lambda$, taking into account the effect of $\lambda$ on the unemployment rate:

(3.3) $\max F(\mu \mathrm{K}, \lambda(1-U) L)$

where $U$ is the unemployment rate, i.e.,

(3.4) $d(\ln Q) / d(\ln \lambda)=\left\{F_{1} \lambda Z^{\prime} K+F_{2}[(1-U) \lambda L]-w \lambda L d U / d(\ln \lambda)\right\} / Q$

$$
\begin{aligned}
& =[r \mu K d(\ln \mu) / d(\ln \lambda)+(1-U) L \lambda w-w \lambda L d U / d(\ln \lambda)] / Q \\
= & s_{k} d(\ln \mu) / d(\ln \lambda)+\left(1-s_{k}\right)\{1+d[\ln (1-U)] / d(\ln \lambda)\}
\end{aligned}
$$

At the private sector optimization, this is $<$ or $>0$ as $\mathrm{dU} / \mathrm{dln} \lambda>$ or $<0$ :

\footnotetext{
${ }^{12}$ See J. Hicks (1932), for a discussion of a typology of innovation.
} 
Proposition 4. There is excessive (insufficient) labor-augmenting innovation if the effect of innovation is to increase (decrease) the unemployment rate, i.e. if $\sigma<(>) 1$.

Empirical estimates suggest that the elasticity of substitution is less than unity. ${ }^{13}$ There is thus a presumption that (in the short run, with fixed $\mathrm{K}$ and $\mathrm{L}$ ), innovation focuses excessively on increasing the productivity of labor. The market does not take into account the effects of laborsaving innovation in increasing unemployment.

By the same token, if social welfare is concerned with the distribution of income (inequality) the market will also lead to excessively labor augmenting innovation, if the elasticity of substitution is less than unity. ${ }^{14}$ If redistributions were costless, lump sum transfers could undo the distributive effects. But redistributions are not costless, so there is a social cost of such innovations.

\section{III.3 Dynamics with unemployment}

We focus on the special case of a fixed coefficients technology (in the short run--in the long run, the capital-labor ratio can change because of induced innovation) and continue with the assumption of a fixed savings rate. Both of these assumptions can be generalized. The assumption of fixed savings rate implies that

(3.5) $\mathrm{dK} / \mathrm{dt}=\mathrm{Sb}$,

where $1 / b$ is the capital output ratio, and

(3.6) $Q=K b$.

We let

(3.7) $\mathrm{aL}=\mathrm{Q}$.

It follows that the rate of growth of employment is

(3.8) $d(\operatorname{lnL}) / d t=S b+d(\operatorname{lnb}) / d t-d(\operatorname{lna}) / d t$.

In steady state, the rate of growth of employment equals the rate of growth of the labor force, $\mathrm{n}$ :

(3.9) ) $n=S b+d(\operatorname{lnb}) / d t-d(\operatorname{lna}) / d t$.

\footnotetext{
${ }^{13}$ See, among others, Antràs (2004), Kalt (1978), and David andvan de Klundert (1965). Piketty (2014) criticizes the finding that the elasticity of substitution is always less than zero. He argues that the data used to draw this conclusion focuses on too narrow a time period. On the other hand, much of his analysis does not make an adequate distinction between wealth and capital (e.g. much of the increase in the value of wealth is related to an increase in the relative price of land; see Stiglitz, 2014).

${ }^{14}$ Assuming, as is the case, that the income of workers is less than that of "capitalists".
} 
Labor and capital augmenting technological progress take on a simple form in this fixedcoefficients model:

(3.10) $m=d(\ln b) / d t$

and

(3.11) $\wedge=d(\operatorname{lna}) / d t$.

\section{III.4 Steady-state equilibrium}

In steady-state equilibrium, it can be shown that $d(\operatorname{lnb}) / d t=0$, which in turn means that equilibrium $\Lambda^{*}$ is given by the solution to

(3.12) $0=Z\left(\wedge^{*}\right)$.

This means in turn that technology adjusts to ensure that, in the long run,

(3.13) $n+\Lambda^{*}=s b^{*}$.

From the discussion of section I, it should be clear that ${ }^{15}$

(3.14) $z\left(\wedge^{*}\right) \equiv-d(\ln Z) / d(\ln \Lambda)=s_{L}^{*} /\left(1-s_{L}^{*}\right)$,

where

(3.15) $\mathrm{s}_{\mathrm{L}}=\mathrm{wL} / \mathrm{Q}=\mathrm{w} / \mathrm{a}$.

Given $\Lambda^{*}$, we can easily solve for $s_{L}^{*}$ (from 3.14). Without ambiguity, we write the solution of (3.14) as $\Lambda\left(s_{L}\right)$.

$$
\Lambda\left(s_{L}\right) \equiv z^{-1}\left[s_{L} /\left(1-s_{L}\right)\right]
$$

In steady state, not surprisingly, the share of labor is constant. We assume that the relationship between wage and productivity is a function of the unemployment rate, i.e. ${ }^{16}$

(3.16) $\mathrm{w}=\mathrm{aM}(U), \mathrm{m}^{\prime}<0$.

Given $\mathrm{S}_{\mathrm{L}}{ }^{*}$, we can solve (3.15) for (w/a)*, and given that, we can easily solve (3.16) for $\mathrm{U}^{*}$, the equilibrium unemployment rate:

(3.17) $U^{*}=M^{-1}\left(s_{L}^{*}\right)$.

\footnotetext{
${ }^{15}$ The costs of production are $w / a+r / b$. As noted earlier, (3.14) can be seen as maximizing the rate of reduction of the unit costs of production.

${ }^{16}$ (3.16) can be thought of as derived from an efficiency wage model, where the efficiency wage is a function of the unemployment rate and the minimum wage, and the minimum wage rises with productivity, i.e. $W_{\min }=\Psi a$, for some constant $\Psi$. The wage an individual then receives is $W=G(U) W_{\min }=G(U) \Psi a$.
} 
In steady state, the unemployment rate is constant: $d(\ln U) / d t=0$. We can now solve for the equilibrium employment rate, $\mathrm{e}=\mathrm{L} / \mathrm{N}$, where $\mathrm{N}$ is the total labor force (population). From the definition of $U$,

$$
U^{*}=1-L / N=1-e^{*}
$$

In steady state, $\mathrm{N}$ grows at the rate $\mathrm{n}$, a grows at the rate $\Lambda^{*}, \mathrm{~K}$ grows at the rate $\mathrm{n}+\lambda^{*}, \mathrm{~b}$ (the capital output ratio) is constant, the employment ratio is constant, and the share of labor is constant.

\section{III.5 Stability}

The dynamics of the economy are straightforward. In early models of growth with fixed coefficients, it was observed that if $\mathrm{Sb}>\mathrm{n}$, the demand for labor grew at a rate faster than the labor force, and eventually the economy would face a problem of insufficient labor supply. Solow (1956) provided an answer. There are not fixed coefficients, so that b, the output capital ratio, would fall as the capital-labor ratio increased. Here, we provide an alternative resolution. As the unemployment rate decreases, wages (per efficiency unit) increase, increasing the share of labor, and inducing labor-saving and capital-using innovation. Again, b, the output capital ratio falls. And it continues to fall until $\mathrm{Sb}=\mathrm{n}$.

More formally, we can describe the dynamics by a pair of differential equations. First note that (3.19) $) L=Q / a=(b / a) K$

and

(3.20) $e=(b / a)(K / N)$.

Hence

(3.21) $d($ Ine $) / d t=S b+z\left(\Lambda\left(s_{L}\right)\right)-\Lambda\left(s_{L}\right)-n$.

The dynamics are described fully by (3.21) and

$(3.22) d(\operatorname{lnb}) / d t=z\left(\wedge\left(s_{L}\right)\right)$

where

$(3.23) \wedge\left(s_{L}\right) \equiv=\wedge(M(1-e))$.

The phase diagram is depicted in Figure 5.

(3.24) $d(\operatorname{lnb}) / d t=0$ when $e=e^{*}$.

(3.25) $d($ Ine $) / d t=0$ when $b=\left[n-Z\left(\Lambda\left(s_{L}{ }^{*}\right)\right)+\Lambda\left(s_{L}{ }^{*}\right)\right] / S$.

The $d($ Ine $) / d t=0$ curve is downward sloping. 
An increase in the employment rate leads to an increase in wages, which leads to more laboraugmenting and less capital-augmenting progress, i.e. $b$ falls, so $\mathrm{db} / \mathrm{dt}<0$ to the right of the $\mathrm{db} / \mathrm{dt}=0$ locus. Similarly, an increase in b leads to an increase in $\mathrm{dln}$ e/dt, i.e. $\mathrm{de} / \mathrm{dt}>0$ above the $\mathrm{de} / \mathrm{dt}=0$ locus. The economy oscillates into an equilibrium. ${ }^{17}$

\section{Skill biased innovation}

The same kind of analysis applies if we extend the model to innovation that is "skill-biased." Assume, for instance that

$$
Q=F\left(\lambda_{s} L_{s}, \lambda_{u} L_{u}\right)
$$

where $L_{s}$ is the input of skilled labor, $L_{u}$ that of unskilled labor, and $\lambda_{s}$ and $\lambda_{u}$ is the level of skillaugmenting and unskilled-augmenting technological progress, with an innovation frontier

$$
\lambda_{\mathrm{u}}=\mathrm{Z}\left(\lambda_{\mathrm{s}}\right)
$$

As before, the market allocation will pay no attention to distributive and unemployment effects of the choices it makes.

For instance, if employers can distinguish who is skilled and unskilled, there will be a different no-shirking curve (as in the Shapiro-Stiglitz model) for each group. A change in the skill bias of technological change will typically shift the demand curve for one group of workers up and the other down, leading to a reduction of one type of unemployment and an increase in the other. If monitoring is, say, more difficult for unskilled workers than for skilled workers, unskilled worker unemployment may be more important. (In the limit, if the performance of skilled workers was perfectly observable, then there would be no efficiency-wage unemployment of skilled workers, only of unskilled workers.) It follows then, from the same logic as used earlier, that if the elasticity of substitution between skilled and unskilled workers is less than unity, that the market equilibrium will be associated with excessively skill-biased technological progress.

At the end of section 2, we observed that if the elasticity of substitution is greater than unity, then the long-run equilibrium may be unstable. An increase in the share of capital leads to a bias toward further capital-augmenting technological progress, further increasing the share of capital. The same logic applies as well to innovation augmenting the productivity of skilled and unskilled workers. In the case of a low elasticity of substitution, if productivity of the highly skilled workers increases relative to unskilled, the share of skilled workers goes down, and this then leads to reduced incentives for such innovation. But if the elasticity of substitution is large, then the share of income going to skilled workers increases, and the bias increases. The implication is that the ratio of income (wages) of skilled and unskilled workers increases (without bound), with increasing incentives for more skill-biased innovation.

\footnotetext{
${ }^{17}$ Standard techniques can be used to show that the equilibrium is, in general, stable.
} 
There are peculiar long-run implications of such an analysis. The share of skilled labor would increase toward unity. It also means that the return to converting an unskilled worker into a skilled worker increases (again without bound). An increasingly large fraction of the labor force would thus become "educated." If there are increasing costs associated with converting the marginal unskilled worker into a skilled worker, at each date there will be a residual of unskilled workers, suffering from increasing relative deprivation.

But again, there may be an equilibrating force, as skilled-labor-augmenting technological progress becomes increasingly difficult, especially relative to say capital or unskilled-biased technological change.

\section{Concluding Comments}

\section{Interpretations}

In the standard neoclassical model, factor supplies (including the [given] relative productivities of different factors) determine the distribution of income. In the Solow (1956) growth model, however, the long-run rate of growth itself does not in any way depend on the distribution of income. ${ }^{18}$ Moreover, there is always full employment. If there is unemployment, there is only one reason: wage rigidities. Conventional discourse attributes wage rigidities either to what the government does (minimum wages) or what it does not do (circumscribing unions). Eliminating such rigidities increases efficiency and eliminates unemployment. With a high elasticity of substitution, a relatively small change in the wage will return the economy to full employment, so that not even workers will suffer much. (Though firms choose the technology to employ, factor prices always adjust so that the technology they choose is such that factors are fully employed.)

Here, the distribution of income matters a great deal: it determines the pattern of innovation. And wage rigidities are a consequence of market forces--given imperfections of information, it benefits firms to pay wages above the market-clearing level. This model provides a far better interpretation of the pattern of unemployment than that which attributes unemployment either to minimum wages or unions; for we see high levels of unemployment both in nonunionized sectors and at skill levels far above those for which the minimum wage is relevant.

But these high wages provide firms with an incentive to reduce the demand for labor by innovation, leading to a still higher (equilibrium) level of unemployment. The market on its own is inefficient, both in the level of unemployment ${ }^{19}$ and, importantly, in the pattern of innovation. Moreover, if the elasticity of substitution (ex post) is low, as in the model presented in section III, then to achieve full or even significantly fuller employment in the short run may

\footnotetext{
${ }^{18}$ And this is even true in Kaldorian variants of that model, where the savings rate is dependent on the distribution of income, or on more neoclassical variants of that model, where the savings rate is determined endogenously.

${ }^{19}$ As demonstrated in Shapiro and Stiglitz (1984)
} 
require a large reduction in wages. Indeed, it may not even be possible to achieve full employment. The short-run effect of lowering wages on employment may be nil.

The efficiency wage model is the simplest within which to explore market distortions in the pattern of innovation, but similar results emerge in other models with (endogenous) market imperfections. Economic historians, such as Salter (1962) and Habbakuk (1962) have emphasized the role of "labor scarcity" as an inducement to labor-saving innovation. (Such explanations seem to have special relevance in particular historical periods, e.g., in the period of the rapid expansion of the United States in the nineteenth century.) Standard economic theory has had a hard time understanding what labor scarcity might mean, other than a high price (or share) of labor. ${ }^{20}$ But in models with costly information and highly differentiated labor, there is a natural interpretation. It may take time and resources to recruit a new worker to replace a worker that leaves. Labor-augmenting technological progress reduces not only the direct labor costs, but these indirect turnover (search and recruitment) costs. But in economies with costly search, a decision by a firm to engage in more labor-augmenting technological progress-and thus in less recruitment-imposes externalities on other market participants, both on workers (who must now search longer to find a job) and on other firms (who now may face lower recruitment costs). Again, there is no presumption that the market equilibrium factor bias will be efficient; indeed, there is a presumption that it will not be (see Greenwald and Stiglitz 1988; Arnott and Stiglitz 1985).

More generally, we note that from the perspective of the firm, what matters is not just the wage or interest rate, as these might show up in the system of national income accounts, but the effective total labor and capital costs, which can differ markedly from the recorded labor and capital shares, for several reasons. First, because of taxes and fringe benefits, the cost of labor to the firm may exceed the wage that workers receive by a considerable margin. Second, if there is credit rationing, the "shadow" cost of capital may well exceed the interest rate charged; and if firms can't instantaneously hire workers of the particular type in which they are interested (there is, in this sense, a labor scarcity), then the shadow cost of labor will exceed the wage. Even a relatively small gap in time in being able to fill a position may be costly. By the same token, if machines are not fully reliable and cannot be easily replaced, a breakdown of a machine can be costly. Thirdly, workers have to be managed. Strikes are costly. All of this requires scarce managerial time.

When a firm assesses whether to save on labor or capital, all of these costs are relevant.

\section{Policy Implications}

There are several important policy implications of this analysis. First, policies that increase the national savings rate can be an effective way of increasing employment in the medium term.

\footnotetext{
${ }^{20}$ There are other interpretations, discussed further briefly below. It seems, for instance, that at times wages did not fully adjust, and that at times, as a result, firms had difficult times hiring workers. This will result in the shadow wage exceeding the market wage.
} 
(This is especially true in the model presented in section 3, where there is zero ex post elasticity of substitution.)

Second, wage subsidies reduce the cost of labor, and it is the high cost of labor that induces firms to shift the direction of technological development toward excessive labor-saving and capital-using technologies. By the same token, when the Fed lowers the cost of capital dramatically (as it attempted to do after the Great Recession), it encourages labor-saving innovation. Thus, we observe the curious phenomenon of firms replacing unskilled labor (with presumably a low "social" shadow price, given the high unemployment rate among unskilled workers), such as checkout clerks with automatic tellers. While there are almost surely social benefits from the induced employment resulting from the increased aggregate demand from such investments, those benefits have to be set against the social costs of higher unemployment in the medium term as a result of the labor-saving innovation induced by the lowering of the cost of capital. A full analysis of the intertemporal trade-offs would take us beyond the confines of this discussion.

Third, increasing the price paid by firms for environmental impacts (e.g. as a result of carbon emissions) shifts innovation away from labor-saving (augmenting) innovation, again with positive effects on the distribution of income and employment.

\section{Toward a More General Theory}

By bringing together a plausible theory of wage determination with the theory of induced innovation, we have provided a general theory of growth and employment which makes sense of discussions of technological unemployment or job shortages-concepts that have no meaning in Solow's formulation. In this theory the distribution of income matters; it affects technology and the dynamics of the economy, and these in turn affect the distribution of income at later dates. ${ }^{21}$

Recent discussions of persistent unemployment and growing inequality have centered around labor-saving innovations, and in particular on skill-biased innovation. ${ }^{22}$ Critics of such innovation are sometimes referred to as modern-day Luddites, and defenders of the market have claimed that one should not interfere with market processes. In the long run, they argue, everyone will be better off. Our analysis has suggested that such views may be Panglossian. Not only within their life-span may workers not be better off-the benefits of the

\footnotetext{
${ }^{21}$ We also note that the dynamics can be markedly different from those of the standard Solow model, where convergence to equilibrium is monotonic. As we noted, convergence is oscillatory. This is true both in models with full employment and unemployment induced by efficiency wage considerations. We have also uncovered a fundamental dynamic instability in the case of elasticity of substitution greater than unity. We should observe, however, that the smooth convergence to the steady state in the Solow model is a function of its extreme simplifying assumptions. Other slight modifications (vintage capital, savings depending on the distribution of income) can also lead to more complicated dynamics. See, e.g. Akerlof and Stiglitz (1969), Cass and Stiglitz (1969) or Stiglitz (1967).

${ }^{22}$ Autor and Dorn (2013).
} 
improvements may not trickle down-but additionally, the changes in factor demands may actually lead them to be worse off even in the longer run. ${ }^{23}$

We have shown not only that innovations may fail to improve the welfare of all groups in society-they may not result in Pareto improvement-but also that the outcome of market processes may lead to patterns of innovation that are not even output maximizing - they would not be Pareto efficient even if redistributions could be made costlessly. ${ }^{24}$ Indeed, there is a presumption that unfettered markets will not be efficient in the choice of factor bias, and will lead to excessively high levels of unemployment.

\section{$\underline{\text { References }}$}

Acemoglu, D, "When Does Labor Scarcity Encourage Innovation?," Journal of Political Economy, Vol. 118, No. 6 (December 2010), pp. 1037-1078

Ahmad, S., 1966, "On the Theory of Induced Innovation," Economic Journal, 76, June, pp. 344357

Akerlof, G. and J. E. Stiglitz, 1969, "Capital, Wages and Structural Unemployment," Economic Journal, 79(314), June, 1969, pp. 269-281.

Antràs P., 2004, "Is the US Aggregate Production Function Cobb-Douglas? New Estimates of the Elasticity of Substitution," Berkeley Electronic Journals in Macroeconomics: Contributions to Macroeconomics, 4 (1): article 4.

Arnott, R. and J. E. Stiglitz, 1985, "Labor Turnover, Wage Structure \& Moral Hazard: The Inefficiency of Competitive Markets,", Journal of Labor Economics, 3(4), October, pp. 434-462. Reprinted in The Selected Works of Joseph E. Stiglitz, Volume II:

Information and Economic Analysis: Applications to Capital, Labor, and Product Markets, Oxford: Oxford University Press, 2013pp. 581-600.

Autor, D.H. and D. Dorn, 2013, "The Growth of Low Skill Service Jobs and the Polarization of the U.S. Labor Market" American Economic Review (forthcoming)

Autor, D.H., F. Levy, and R.J. Murnane. 2003, "The Skill Content of Recent Technological Change: An Empirical Investigation." Quarterly Journal of Economics, 118(4), November.

Autor, D.H., L.F. Katz, and Melissa S. Kearney. 2008, "Trends in U.S. Wage Inequality: Revising the Revisionists." Review of Economics and Statistics. 90(2), May, 300-323

Cass, D. and J.E. Stiglitz "The Implications of Alternative Saving and Expectations Hypotheses for Choices of Technique and Patterns of Growth", Journal of Political Economy, 77, JulyAugust 1969, pp. 586-627.

\footnotetext{
${ }^{23}$ This is consistent with the evidence on the stagnation of median and mean wages in the US over a span of more than forty years, and a decline in mean and median wages of unskilled workers (e.g. workers with only a high school education).

${ }^{24}$ This may, of course, also be true with other forms of market frictions, e.g. imperfect labor mobility. See, e.g. Delli Gatti et al 2012, 2013.
} 
David, P.A. and Th. van de Klundert, 1965, "Biased Efficiency Growth and Capital-Labor Substitution in the U.S., 1899-1960," American Economic Review, 55(3): 357-393.

Delli Gatti, D., M. Gallegati, B. Greenwald, A. Russo, and J. E. Stiglitz, 2012, “Mobility Constraints, Productivity Trends, and Extended Crises," Journal of Economic Behavior \& Organization, 83(3): 375- 393.

- - , - , - - - - , and - - 2013, "Sectoral Imbalances and Long Run Crises," in The Global Macro Economy and Finance, F. Allen, M. Aoki, J.-P. Fitoussi, N. Kiyotaki, R. Gordon, and J.E. Stiglitz, eds., IEA Conference Volume No. 150-III, Houndmills, UK and New York: Palgrave, pp. 61-97.

Drandakis, E. M., and ER. S. Phelps, "A Model of Induced Invention, Growth, and Distribution," Economic Journal, 76, December 1966, pp. 832-840Fellner (1961)

Greenwald, B. and J. E. Stiglitz, "Pareto Inefficiency of Market Economies: Search and Efficiency Wage Models," American Economic Review, 78(2), May 1988, pp. 351-355.

- - and J. E. Stiglitz. 1986. "Externalities in Economies with Imperfect Information and Incomplete Markets." Quarterly Journal of Economics 1(2, May): 229-264.

- - and J. Kahn, 2009, Globalization: $n$. The Irrational Fear That Someone in China Will Take Your Job, Hoboken, N.J. : John Wiley \& Sons.Goldin and Katz.

Greiner, Alfred, Jens Rubart, and Willi Semmler, 2003, "Economic Growth, Skill-Biased Technical Change and Wage Inequality: A Model and Estimations for the U.S. and Europe," New School working paper, available at http://www.newschool.edu/nssr/cem/papers/wp/labor/wineq.pdf (accessed February $27,2013)$.

Habakkuk, H.J., 1962, American and British Technology in the Nineteenth Century, London: Cambridge Univ. Press.

Hicks, J., 1932, Theory of Wages, London : Macmillan ; New York : St. Martin's Press.

Kennedy, C., 1964, "Induced Bias in Innovation and the Theory of Distribution," Economic Journal, pp. 541-547

Kalt, J.P., 1978, "Technological Change and Factor Substitution in the United States: 19291967", International Economic Review, 19(3): 761-775.

Piketty, T., 2014, Capital in the Twenty-First Century, Cambridge, Mass., and London: The Belknap Press of Harvard University Press.

Salter, W.E.G., 1962, Productivity and Technical Change, Cambridge: Cambridge University Press (second edition, 1966).

Samuelson, P., 1966, "A Theory of Induced Innovation along Kennedy-Weizacker Lines," Review of Economics and Statistics, 33, pp. 133-146. 
Shapiro, C. and J.E. Stiglitz, 1984, "Equilibrium Unemployment as a Worker Discipline Device," American Economic Review, 74(3): 433-444

Solow, R.M., 1956, "A Contribution to the Theory of Economic Growth," Quarterly Journal of Economics LXX, pp. 65-94

Stiglitz, J.E., 1967, "A Two-Sector, Two Class Model of Economic Growth," Review of Economic Studies, 34, April, pp. 227-238

- - 2014, " The Measurement of Wealth: Recessions, Sustainability, and Inequality ", presented at the International Economic Association World Congress, Dead Sea, Jordan, June, 2014. 


\section{Figure Labels}

\section{Figure 1}

Innovation Possibilities Frontier. There is a trade-off between the rate of capital augmenting technological progress, $\mu$ and the rate of labor augmenting technological progress, $\lambda$. Market equilibrium is at point where the elasticity of the curve $z(\lambda) \equiv d \ln Z / d \ln \lambda$ equals the relative shares, $w L \lambda / r \mu \mathrm{K}=\mathrm{s}_{\mathrm{L}} / \mathrm{s}_{\mathrm{K}}$

\section{Figure 2}

Determination of Factor Bias of Technological Change: Panel A. Elasticity of substitution less than unity. There is a unique value of $\lambda$ for which the elasticity of the innovation curve equals the relative shares. Panel B. Elasticity of substitution greater than unity. There may be multiple values of $\lambda$ for which the elasticity of the innovation curve equals relative shares.

\section{Figure 3}

Figure 3: Steady states and dynamics. The steady state is given by the intersection of the curves giving $\mathrm{d} \mu / \mathrm{dt}=0$ and $\mathrm{d} \mathrm{k} / \mathrm{dt}=0$. In all cases, the former curve(s) is a vertical straight line. Panel A. Elasticity of substitution less than unity. The $\mathrm{d} \mathrm{k} / \mathrm{dt}=0$ locus is upward sloping, the equilibrium is stable, and the convergence is oscillatory. Panel B. elasticity of substitution greater than unity. The $\mathrm{d} \mathrm{k} / \mathrm{dt}=0$ locus is an inverted $U$ shaped (it can actually be more complicated than that.) There is a unique interior steady state, which is a saddle point. Above the convergent trajectory, $\mu$ and $\mathrm{k}$ both go off to infinity; below, to zero. Panel $\mathrm{C}$. If the elasticity of substitution is both above and below unity (for different values of $\mathrm{k}$ ), then there can exist multiple steady states. Here, we illustrate a case with three, with the middle, $E_{2}$, being unstable, and the other two (locally) stable.

\section{Figure 4}

Effect of labor augmenting innovation in Shapiro-Stiglitz model. If the demand curve for labor shifts down, then labor augmenting technological progress leads to more unemployment. The market does not take into account the social costs of this induced unemployment.

\section{Figure 5}

Dynamics of adjustment. Convergence to equilibrium may be cyclical. 


\section{Figures}

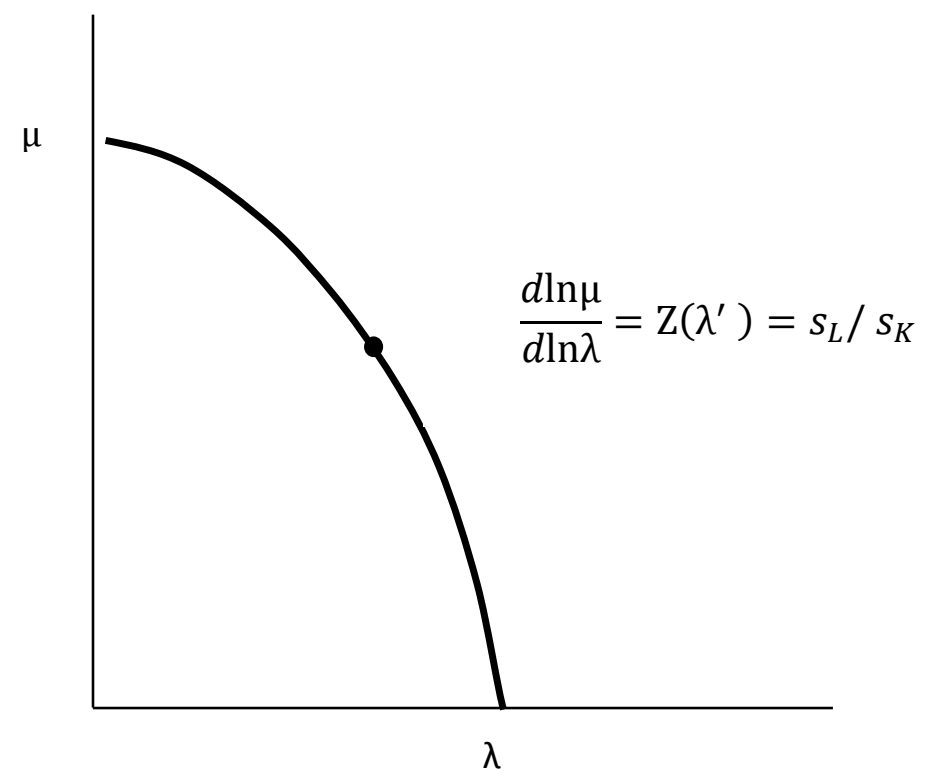

Figure 1 


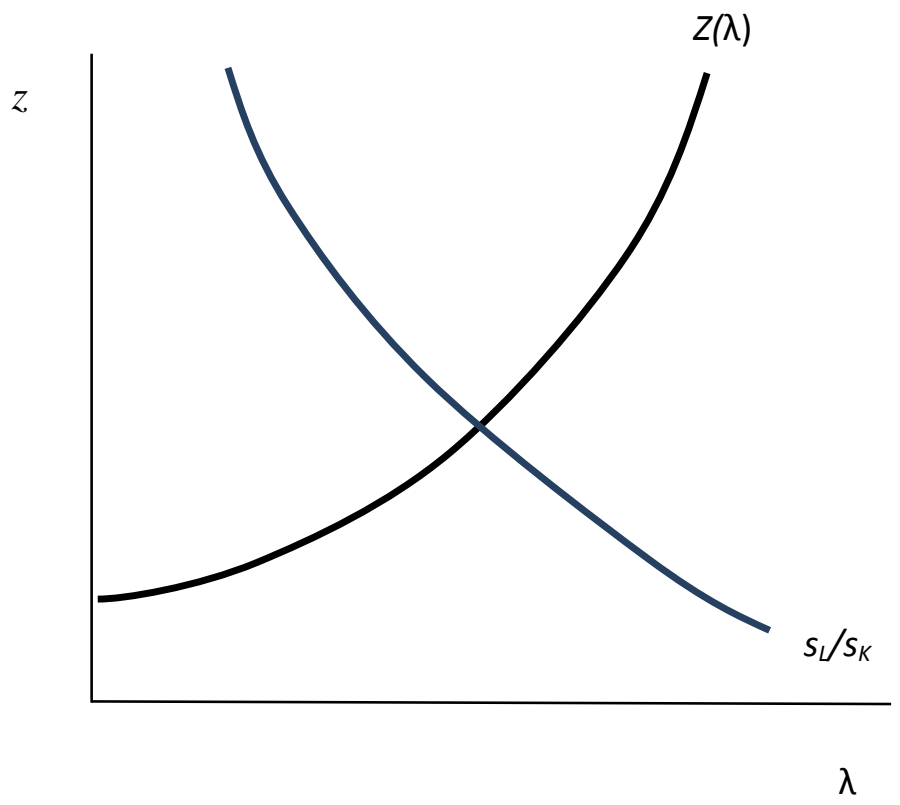

Figure $2 \mathrm{~A}$

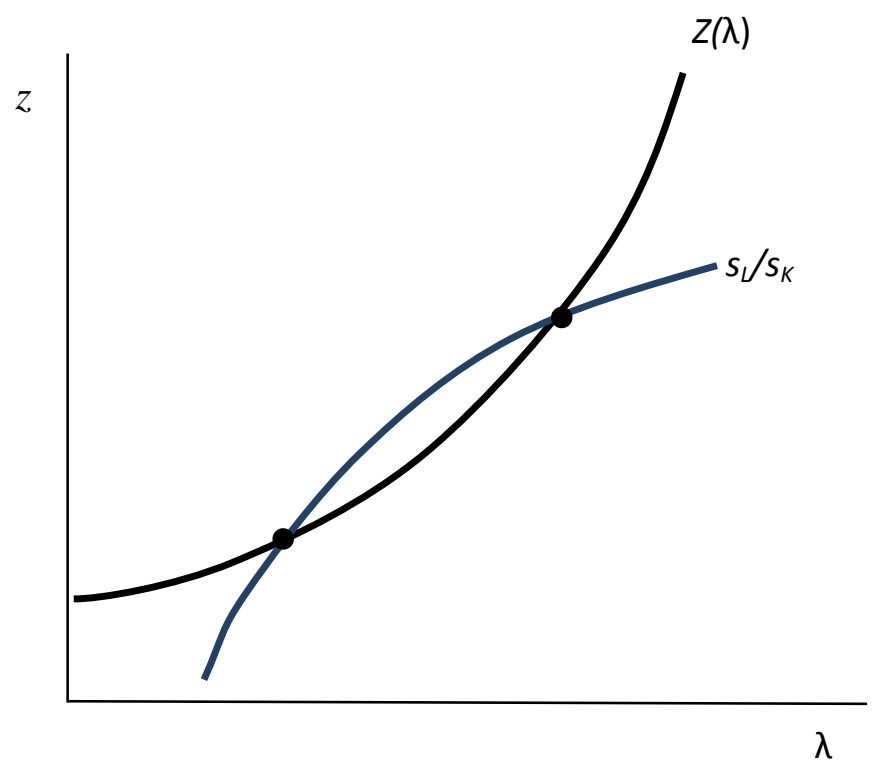

Figure 2B 


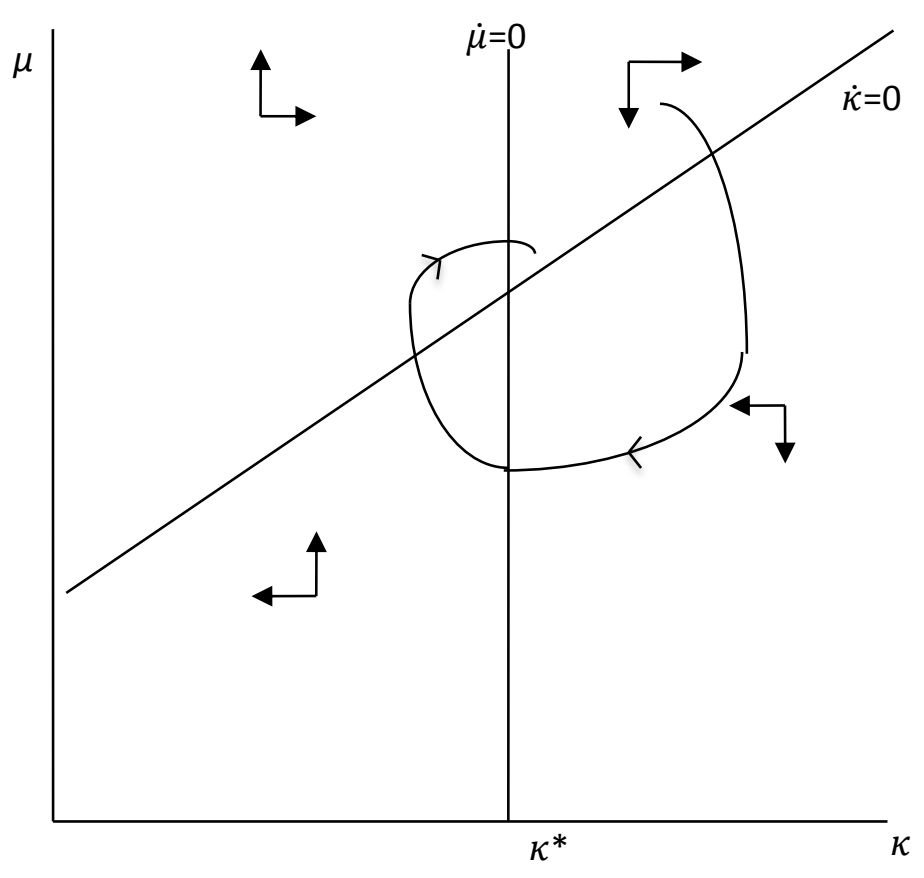

Figure $3 \mathrm{~A}$

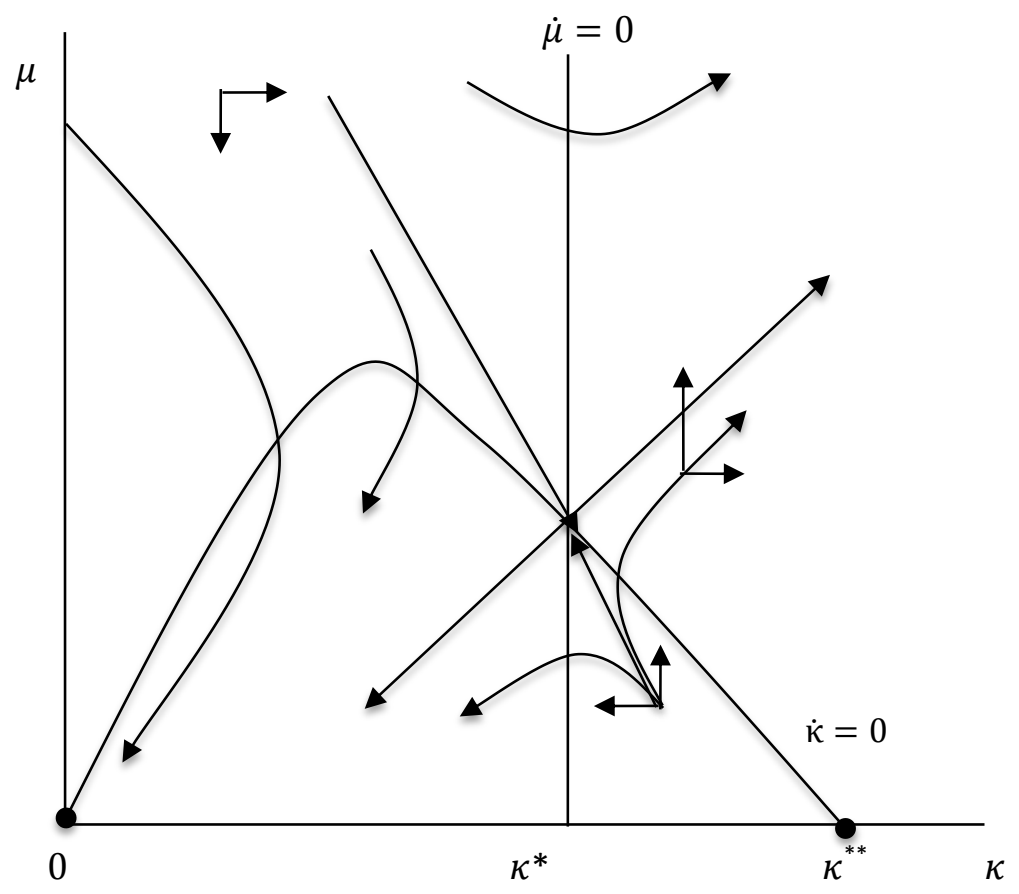

Figure 3B 


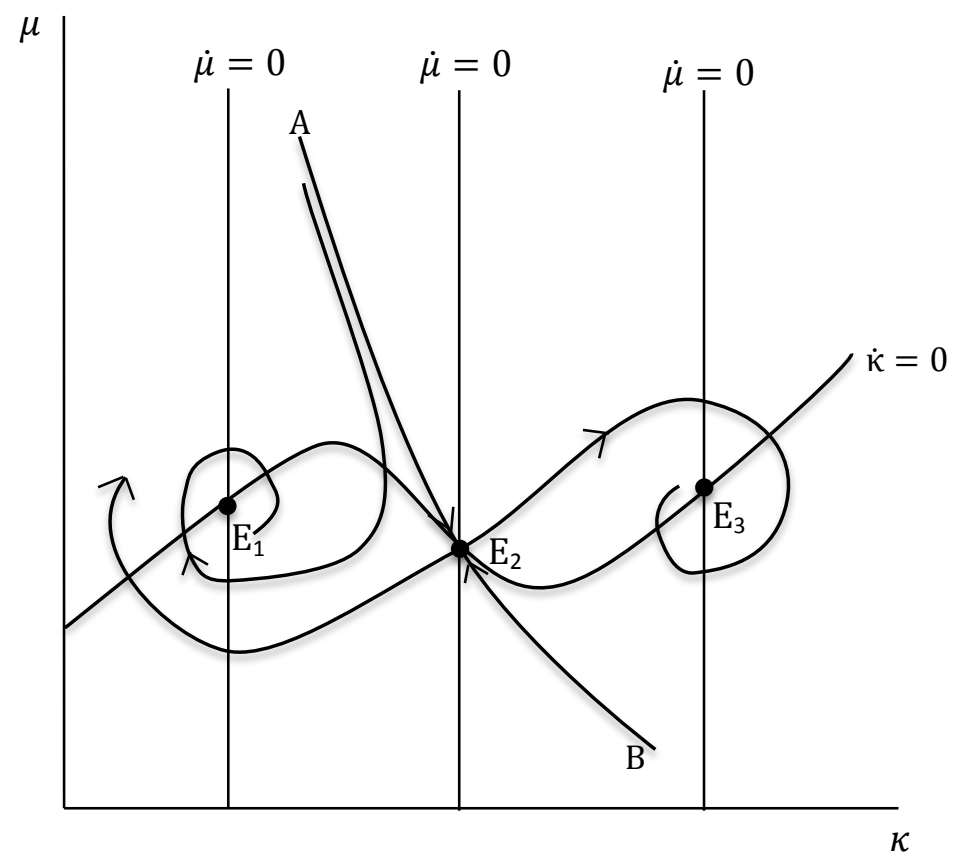

Figure $3 C$ 


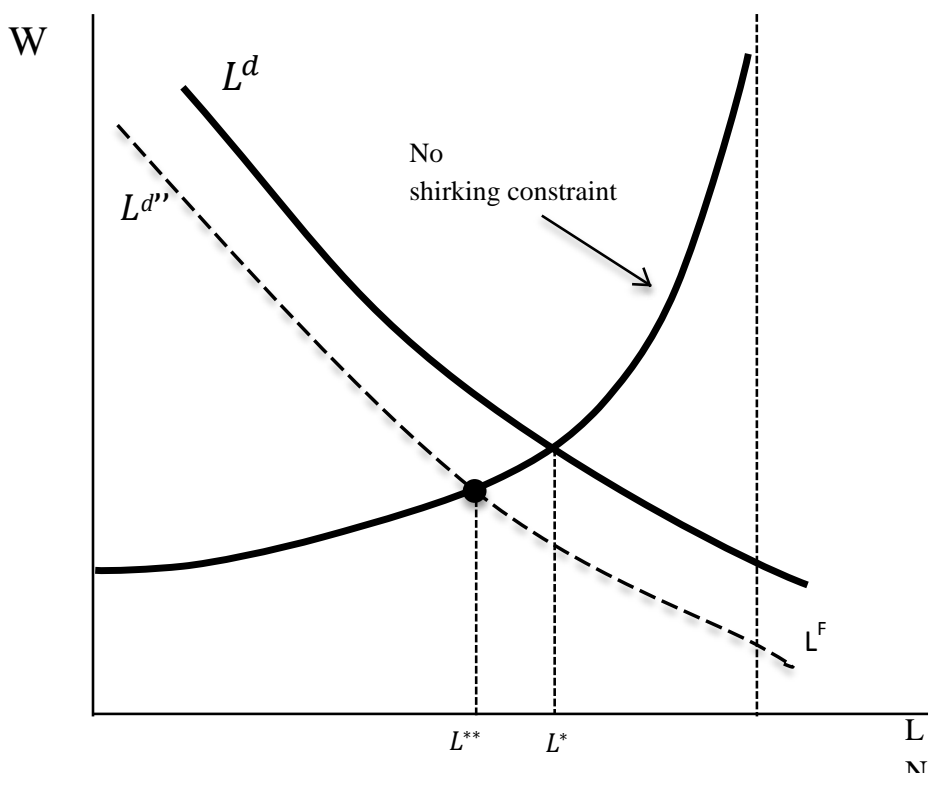

Figure 4

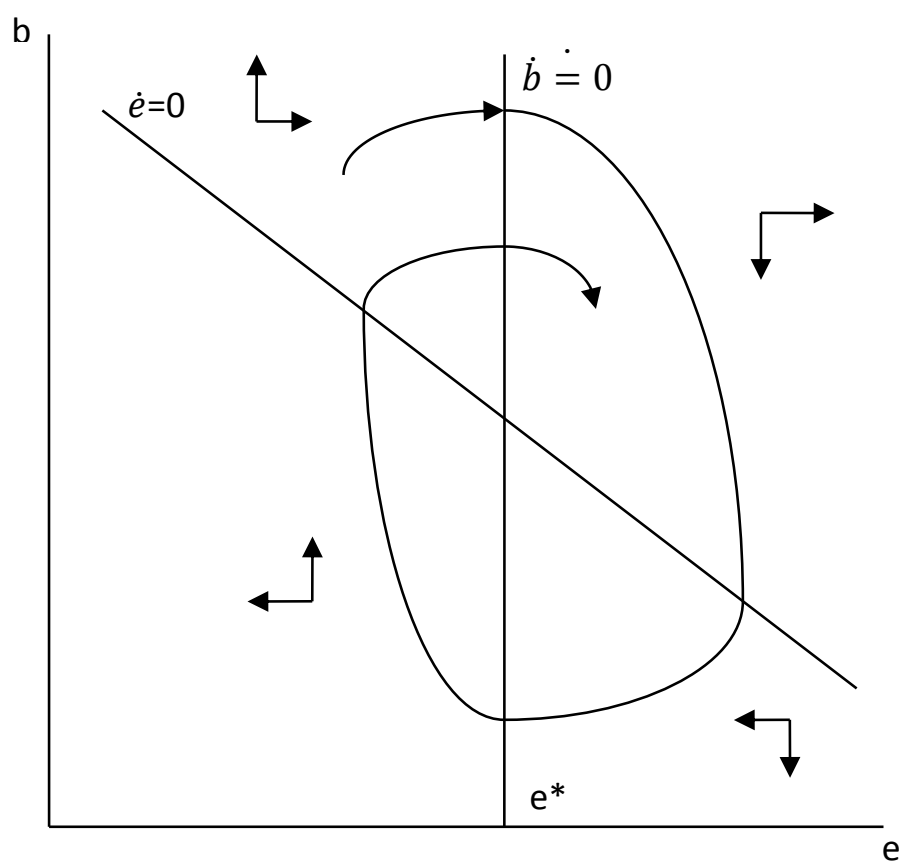

Figure 5 